medRxiv preprint doi: https://doi.org/10.1101/2021.05.01.21256463; this version posted May 4, 2021. The copyright holder for this preprint

(which was not certified by peer review) is the author/funder, who has granted medRxiv a license to display the preprint in perpetuity. It is made available under a CC-BY-ND 4.0 International license.

\title{
The Effect of Combined Respiratory Muscle Training (cRMT) on dysarthric speech following single CVA: A retrospective pilot study
}

Robert J. Arnold, SLP.D ${ }^{1}$., CCC-SLP, Nina Bausek², Ph.D., Christopher S. Gaskill' ${ }^{3}$, Ph.D., CCC-SLP, Tarek Midani, BSBME, M.Eng. ${ }^{4}$

\section{Affiliations:}

1: Chief Clinical Officer, Applied Clinical Scientist, Southeastern Biocommunication

Associates, LLC., Birmingham, AL, 35216, USA. robert.arnold@sba.net.co

2: Research Collaborator, Department of Cardiovascular Medicine, Mayo Clinic, Rochester, MN, 55905, USA. nbausek2@gmail.com

3: Consulting Voice Scientist, Southeastern Biocommunication Associates, LLC., Birmingham, AL, 35216. USA. chris.gaskill@gmail.com

4: Consulting Biomedical Engineer, Southeastern Biocommunication Associates, LLC.,

Birmingham, AL, 35216. USA. trkmid@gmail.com

d: corresponding author: nbausek2@gmail.com

\section{Abstract}

Background: Dysarthria frequently occurs as a result of stroke and adversely impacts speech sound production, making it more difficult for the listener to understand what the person with dysarthria is attempting to communicate. This in turn may lead to social isolation, depression, and increased cost of care. Some studies have underscored the importance of respiratory muscle strengthening as it relates to improvement of speech intelligibility. This retrospective investigation examined the effects of a combined Respiratory Muscle Training (cRMT) protocol upon speech intelligibility in persons post single cerebrovascular accident (CVA).

Methods: The clinical data of 10 patients who requested pro bono speech therapy for the diagnosis and treatment of dysarthria following a single stroke was utilized for this study. The intervention group was treated with three 5-minute sessions with cRMT each day for 28 consecutive days. The control group received no cRMT and no other therapeutic exercise intervention during the time period. Respiratory and speech intelligibility were assessed preand post-intervention in terms of peak expiratory flow, subject self-perception of intelligibility, and word level intelligibility.

Results: After 28 days of $\mathrm{cRMT}$, the intervention group exhibited significant gains compared to the control group in PEF (IG: $73.12 \%$ vs CG: $4.66 \%$ ), Self-Perception of Intelligibility (IG: $72.38 \%$ vs CG: $0.83 \%$ ), and the word task of the Assessment of Intelligibility of Dysarthric Speech (AIDS) (IG: 43.92\% vs. CG: 0\%).

Conclusion: These data suggest cRMT is a feasible and effective treatment for improving

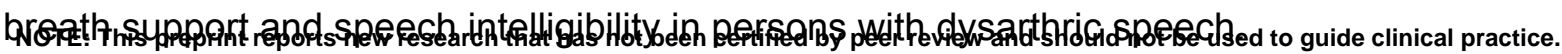


medRxiv preprint doi: https://doi.org/10.1101/2021.05.01.21256463; this version posted May 4, 2021. The copyright holder for this preprint

\section{Introduction}

Approximately 20 to 40 percent of the 5 million stroke survivors per year in the United States of America have a motor speech disorder known as dysarthria, rendering a population of 1 to 2 million living with this disorder [1-5]. In the United Kingdom, about 1 in 53 persons (1.2 million) in the total population are stroke survivors, of whom 30 to $40 \%$ have had dysarthria at some stage [6]. Dysarthria causes distortions of speech sounds decreasing the ability of the listener to comprehend the content and emotion messages the speaker intends to convey. Severe dysarthria can even render the affected person's speech totally unintelligible.

Stroke-induced dysarthrias may restrict social interactions, leading to isolation and depression. It is interesting to note, however, that the severity of dysarthric speech is not always congruent with the psychosocial impact, as even mild dysarthria may have a significant impact [7]. Dysarthria can result in impaired self-identity, dysfunctional relationships, emotional disruptions, and even perceptions of being stigmatized [8]. In contrast to the evidence for the psychosocial impact of dysarthria following stroke, the socioeconomic and financial burden appears largely uninvestigated. Although the cost of stroke and dysphagia is well documented, little investigation has been conducted with regards to the personal financial hardships and societal financial impacts of dysarthria [9]. The ACT NoW study found that speech therapy in patients with dysarthria following stroke may be beneficial if delivered early, at an estimated cost of at least GBP25,000 (approximately USD 35,000) to gain one unit of utility (e.g. Therapy Outcome Measure [TOM]) [10]. Dysarthria, dysphonia, and dysphagia are frequent comorbidities as impaired glottic closure is often a common finding following CVA [11-13].

Evaluation of the speech clarity of persons with dysarthria has evolved over time. A taxonomy for the classification of the dysarthrias was developed at the Mayo Clinic 
medRxiv preprint doi: https://doi.org/10.1101/2021.05.01.21256463; this version posted May 4, 2021. The copyright holder for this preprint

[14-17].This data described flaccid, spastic, ataxic, and some mixed types of dysarthria (e.g. spastic-flaccid) in the stroke population. Furthermore, the Mayo Clinic data enabled clinicians to have a general idea of where the damage from a given stroke had occurred in the central nervous system. For example, flaccid dysarthria results from lower motor neuron damage, while spastic dysarthria results from upper motor neuron damage. Identification of dysarthria subtype is vital for appropriate treatment selection.

The clinical characteristics of dysarthric speech following stroke include rate of speech, prosody, resonance, phonation, articulation, and overall intelligibility. These factors can be evaluated through perceptual, acoustic, manometric, and palatographic means [16-22]. One commonly used clinical tool with adult populations is the Assessment of Intelligibility of Dysarthric Speech (AIDS) [23] which evaluates speech intelligibility at the word level and sentence level and provides a percentage of the intelligibility of speech at both levels. Objective measurements of lip, tongue, and jaw muscle strength and endurance, as they relate to speech and swallow functions, may provide additional insights into function and dysfunction of relevant muscle groups. Several recently developed technologies provide tools for specific evaluation [24-27]. Furthermore, some clinical researchers have asserted that if a given patient can continuously generate subglottic air pressure of $5 \mathrm{~cm} \mathrm{of} \mathrm{H}_{2} \mathrm{O}$ for at least 5 seconds or more, then the respiratory system is likely to be adequate for supporting speech efforts [18]. Use of this pressure generating capability alone may offer a limited perspective, as persons with neuromuscular respiratory deficits may be able to perform this simple static task, but still be unable to sufficiently perform the complex, dynamic respiratory and articulatory movements required for the demands of speech.

Respiratory muscle weakness (RMW) has been identified as being a contributor to loss of intelligible speech following CVA. Early evidence presumed that the most limiting factor in breath support for speech in the presence of dysarthria was the lack of efficiency of valving of the exhalatory airstream $[28,29]$. An advancement in understanding of the support provided by the respiratory system for dysarthric persons was made with the realization that 
medRxiv preprint doi: https://doi.org/10.1101/2021.05.01.21256463; this version posted May 4, 2021. The copyright holder for this preprint

the use of a relatively high lung volume at the onset of speech could improve the intelligibility of speech clarity [30]. Respiratory muscle weakness has since been recognized as a significant contributor to physiological disorders of the upper aerodigestive tract including dyspnea and dystussia [31], and evidence-based treatment paradigms have begun to emerge $[32,33]$. More recently, research has revealed the importance and effectiveness of respiratory strengthening for the treatment of other physiological disorders of the upper aerodigestive tract including dysphagia, dysphonia, and dysarthria [33-38].

Traditional approaches have included coaching of slow rate, breathing exercises, over-articulation, and active resistance oral range of motion tasks. Newer approaches include Lee Silverman Voice Therapy (LSVT) $[39,40]$ and Expiratory Muscle Strength Training (EMST) [41], as well as some emerging concepts with Augmentative \& Alternative Communication (AAC) systems and voice banking including VOCALiD [42-45]. Respiratory Muscle Weakness (RMW) has been found to be prevalent in patients with dysarthria and/or dysphagia following stroke, and amenable to respiratory muscle strengthening [46]. A pilot study using respiratory muscle training (RMT), strengthening both the inspiratory and expiratory muscles, resulted in improvement of several aspects of the disease, including fatigue, respiratory muscle strength, lung volume, and voice clarity [47]. As RMW is a significant contributor to dysarthria independent of the subcategory, RMT may therefore be considered a safe and useful therapy approach.

In order to assess the effects of combined Respiratory Muscle Training (cRMT) on speech clarity and breath support, this study investigates the effects of an exercise program using a combined resistive IMST and EMST device (THE BREATHER $\mathbb{B}$, PN Medical Inc., US Patent Number 4,739,987)[48], which allows for strengthening of the muscles of inhalation and exhalation in the same breath cycle $[49,50]$. This retrospective pilot investigation analyzes the effectiveness of a 4-week cRMT program, which has been shown to have positive effects on neurogenic dysphagia [36] and neurogenic dysphonia [37], on the 
medRxiv preprint doi: https://doi.org/10.1101/2021.05.01.21256463; this version posted May 4, 2021. The copyright holder for this preprint

improvement of speech intelligibility and peak flow in stroke patients diagnosed with dysarthria following a single cerebrovascular accident (CVA).

\section{Methods}

The source data for this retrospective study was collected at a pro bono clinical speech-language pathology (SLP) clinic, which was run by the Office of Hispanic Ministry at a Catholic church in the Greater Birmingham Area of Alabama between 1998 and 2010. This study was granted an Institutional Review Board (IRB) exemption by the Western Institutional Board. All participants included in the study presented with dysarthria following a neurologist confirmed single CVA. As there was a lag between diagnosis and an available treatment opportunity, patients were offered a choice to be instructed in CRMT in the interim, which included explanation, demonstration, and return demonstration. Patients who chose to participate in the cRMT protocol were included in the intervention group (IG), while those who chose not to use the device while waiting for treatment were considered as the control group (CG) for analysis.

Participants included in the analysis had no prior neurological history, no history of dysarthria prior to their CVA, no pharmacological or surgical interventions, and no additional therapy for speech, swallow, or voice during the study period. Furthermore, no other allied health therapy services which may have resulted in some degree of improvement of articulatory, vocal fold, or respiratory functioning (e.g. occupational therapy, physical therapy, respiratory therapy, music therapy, etc.) were administered during the study time period. Lastly, there were no changes in medications noted (e.g. changes in dosage, discontinuation, addition, etc.) during the study time period. Any patients who failed to meet one or more of the inclusion criteria were excluded from this study. The participants' demographic data were reported by age, sex, and race. Additionally, the specification of the hemisphere of CVA was reported. Persons 
medRxiv preprint doi: https://doi.org/10.1101/2021.05.01.21256463; this version posted May 4, 2021. The copyright holder for this preprint

documented to have had an extension of CVA were excluded. While awaiting treatment, all participants were offered a four-week home-based intervention of combined respiratory muscle training (cRMT) using the device.

\section{cRMT Intervention}

The intervention focused on combined respiratory muscle training (cRMT) and was administered using THE BREATHER B. Patients were instructed to sit upright, and to forcefully inhale and exhale through the device using diaphragmatic-abdominal breathing. If necessary, patients were advised to use a nose clip. If patients were unable to maintain a tight lip seal using the mouthpiece of the cRMT device, they were presented with the option to utilize a CPR (cardiopulmonary resuscitation) facemask and received appropriate training. The duration of intervention was 28 days (4 weeks), and included three sessions per day. One session per week was supervised by a therapist. Each treatment day consisted of 3 sessions per day of up to 5 minutes of cRMT per session, as tolerated, judged by the patient's report of fatigue or dizziness and the clinician's assessment of patient fatigue. cRMT intensity was defined as the highest tolerated settings for both inhalation and exhalation.

Settings for inhalation and exhalation were set independently from each other.

Patient compliance and adherence to cRMT were assessed via patient communication during the weekly supervised intervention sessions. During the study duration, the control group received no treatment.

\section{Assessments}

To assess pulmonary function, we assessed peak flow using a peak flow meter (Spir-O-Flow Peak Flow Pocket Monitor, Spirometrics) by taking the average of 3 trials as there is a correlation between peak flow and the pulmonary function required 
medRxiv preprint doi: https://doi.org/10.1101/2021.05.01.21256463; this version posted May 4, 2021. The copyright holder for this preprint

for speech intelligibility. Participants' self-perception of their speech intelligibility was assessed using a visual analogue scale (VAS) with a $100 \mathrm{~mm}$ horizontal line where "0" on the far left represented “My family and friends don't understand anything I say" and " 100 " on the far right represented "My family and friends understand everything I say". Participants judged their own voice both pre- and post-treatment period by placing a vertical hash mark somewhere along the horizontal line. The clinician then measured the distance in millimeters from the left end of the horizontal line to the hash mark, so the speech intelligibility self-perception data is presented as a number from 0 to 100 . Speech intelligibility at the word level was determined by administering the Assessment of Intelligibility of Dysarthric Speech (AIDS), which is an instrument designed to quantify speech intelligibility at the single word level and the sentence level [23]. For the purposes of this retrospective pilot study, only the single word intelligibility was assessed for each participant. The tasks to assess speech intelligibility at the single word level utilizing the AIDS allows the examiner to require the dysarthric speaker to either read single words aloud or, whenever this is not possible due to comorbid visual-perceptual deficits and/or inadequate premorbid reading abilities, to imitate the examiner's spoken model of each word assessed. Of these two methods, the former is considered to be the preferred method. Whichever method was employed in the initial assessment for a given participant on day 1 was also used for follow-up assessment on day 28 for that same participant. Regardless of method, each participant's spoken samples were audio-recorded onto a digital recording device in a quiet room. The recorded samples were then provided to 2 blinded judges who were speech-language pathologists, neither of whom were the examiner. Each judge was provided with a data worksheet copied from the AIDS test manual. The judges were required to listen to each of the 50 words recorded by a given dysarthric speaker. As they listened to each word, the judges would select one word from a field of 12 written possible words on the data worksheet. Once completed, the examiner, using a key of what the actual word was for each of the 50 
medRxiv preprint doi: https://doi.org/10.1101/2021.05.01.21256463; this version posted May 4, 2021. The copyright holder for this preprint

(which was not certified by peer review) is the author/funder, who has granted medRxiv a license to display the preprint in perpetuity.

It is made available under a CC-BY-ND 4.0 International license.

samples, would calculate the percentage of words correctly understood, which

represented the speech intelligibility of the given dysarthric speaker at the word level at that one point in time. Next, the scores of the two judges were averaged to derive the average intelligibility of speech at the word level for data analysis in this study.

\section{Data Analysis}

The primary research question was examined with one multivariate $2 \times 2$ factorial analyses of variance with repeated measures. The between-subjects independent variable was the experimental group (control vs. intervention) and the within-subjects independent variable was time (pretest vs. post test). The three dependent variables were the average of the three peak flow readings, the self-perception of intelligibility, and the word-level intelligibility task.

Univariate analyses followed significant multivariate analyses. The primary focus of the analysis was to determine if there was a significant difference between the control condition and the experimental condition over time due to the intervention. The multivariate interaction effect of time by the experimental group determined whether the two experimental groups changed from the pretest to the post test.

\section{Results}

\section{Demographic and Clinical Data}

This study includes ten participants. Demographic data including gender and age are outlined in table 1. The median age was 69 for the control group and 71 for the intervention group, with no significant difference between the groups ( $p$ Value: 0.85 ).

Table 1 also describes the classification of dysarthria identified in the subjects. According to diagnosis of the referring neurologist, of the five participants in the control group, one patient had a left hemisphere upper motor neuron (UMN) infarct which correlated with the presence 
medRxiv preprint doi: https://doi.org/10.1101/2021.05.01.21256463; this version posted May 4, 2021. The copyright holder for this preprint (which was not certified by peer review) is the author/funder, who has granted medRxiv a license to display the preprint in perpetuity. It is made available under a CC-BY-ND 4.0 International license .

of spastic dysarthria; one patient was diagnosed with a right hemisphere UMN insult and spastic dysarthria; two were diagnosed with lower motor neuron (LMN) infarctions in the brainstem and flaccid dysarthria; and one was diagnosed with a cerebellar infarct and ataxic dysarthria. Out of the five participants in the intervention group, two were diagnosed with left hemisphere UMN infarctions and spastic dysarthria; one was diagnosed with a right hemisphere UMN insult and spastic dysarthria; one was diagnosed with LMN infarct in the brainstem and flaccid dysarthria; and one was diagnosed with a cerebellar infarct and ataxic dysarthria (see Table 1). None of the participants in this study presented with hypokinetic, hyperkinetic, or mixed dysarthria. All participants reported English as their primary language.

Table 1: Distribution of gender and classification of dysarthria in the intervention (IG) and control group (CG).

\begin{tabular}{|r|c|c|c|}
\hline $\mathbf{n}$ & CG & IG & Total \\
\hline Gender & 5 & 5 & 10 \\
\hline Female & 3 & & \\
\hline Male & 2 & 1 & 3 \\
\hline Median Age & 69 & 71 & \\
\hline Classification & 2 & 3 & 5 \\
\hline Spastic Dysarthria & 2 & 1 & 2 \\
\hline Flaccid Dysarthria & 1 & 1 & 3 \\
\hline Ataxic Dysarthria & & & \\
\hline
\end{tabular}

\section{Main Results}

Table 2 outlines the findings from the main assessments of peak flow, speech intelligibility and word-level intelligibility. We first examined whether there was a main effect for time for the set of three dependent variables and second whether there was a difference between 
medRxiv preprint doi: https://doi.org/10.1101/2021.05.01.21256463; this version posted May 4, 2021. The copyright holder for this preprint (which was not certified by peer review) is the author/funder, who has granted medRxiv a license to display the preprint in perpetuity. It is made available under a CC-BY-ND 4.0 International license .

the control and intervention groups over time (Complete results from the statistical analysis are available in supplementary material).

Average peak flow increased by $4.66 \%$ in the control group, while the intervention group showed an increase of $73.12 \%$, corresponding to an improvement of 64.2 liters per minute. Self perception of intelligibility improved by $72.38 \%$ in the intervention group, compared to $0.83 \%$ in the control group, as assessed by VAS. Table 2 further shows that the speech intelligibility at word level improved by $43.92 \%$ in the intervention group, while it did not improve in the control group (0\%). These results demonstrate significant improvements across outcomes in participants who performed cRMT compared to those who did not. The measurements for the participants in the control group remained essentially the same over time, while the participants in the experimental condition showed significant improvement at the posttest. Means for each group, as well as the percent change, are reported in Table 2 .

Table 2: Pre cRMT and post cRMT means and standard error (SE) of average peak flow, self-perception of intelligibility and word-level intelligibility

\begin{tabular}{|c|c|c|c|c|c|c|}
\hline & & \multicolumn{2}{|c|}{ Pre cRMT } & \multicolumn{2}{c|}{ Post cRMT } & \\
\hline & $\begin{array}{c}\text { Experimental } \\
\text { Group }\end{array}$ & Mean & SE & Mean & SE & $\begin{array}{c}\text { Percent } \\
\text { Change }\end{array}$ \\
\hline \multirow{2}{*}{$\begin{array}{c}\text { Average Peak } \\
\text { Flow (L/min) }\end{array}$} & CG & 85.80 & 8.33 & 89.80 & 8.16 & $4.66 \%$ \\
\cline { 2 - 7 } & IG & 87.80 & 9.40 & 152.00 & 12.53 & $73.12 \%$ \\
\hline $\begin{array}{c}\text { Self-perception } \\
\text { of Intelligibility }\end{array}$ & CG & 48.40 & 9.63 & 48.80 & 10.18 & $0.83 \%$ \\
\cline { 2 - 7 } & IG & 42.00 & 8.90 & 72.40 & 7.19 & $72.38 \%$ \\
\hline \multirow{2}{*}{$\begin{array}{c}\text { Word-level } \\
\text { intelligibility }\end{array}$} & IG & 0.59 & 0.10 & 0.85 & 0.06 & $43.92 \%$ \\
\cline { 2 - 7 }
\end{tabular}


medRxiv preprint doi: https://doi.org/10.1101/2021.05.01.21256463; this version posted May 4, 2021. The copyright holder for this preprint (which was not certified by peer review) is the author/funder, who has granted medRxiv a license to display the preprint in perpetuity. It is made available under a CC-BY-ND 4.0 International license.
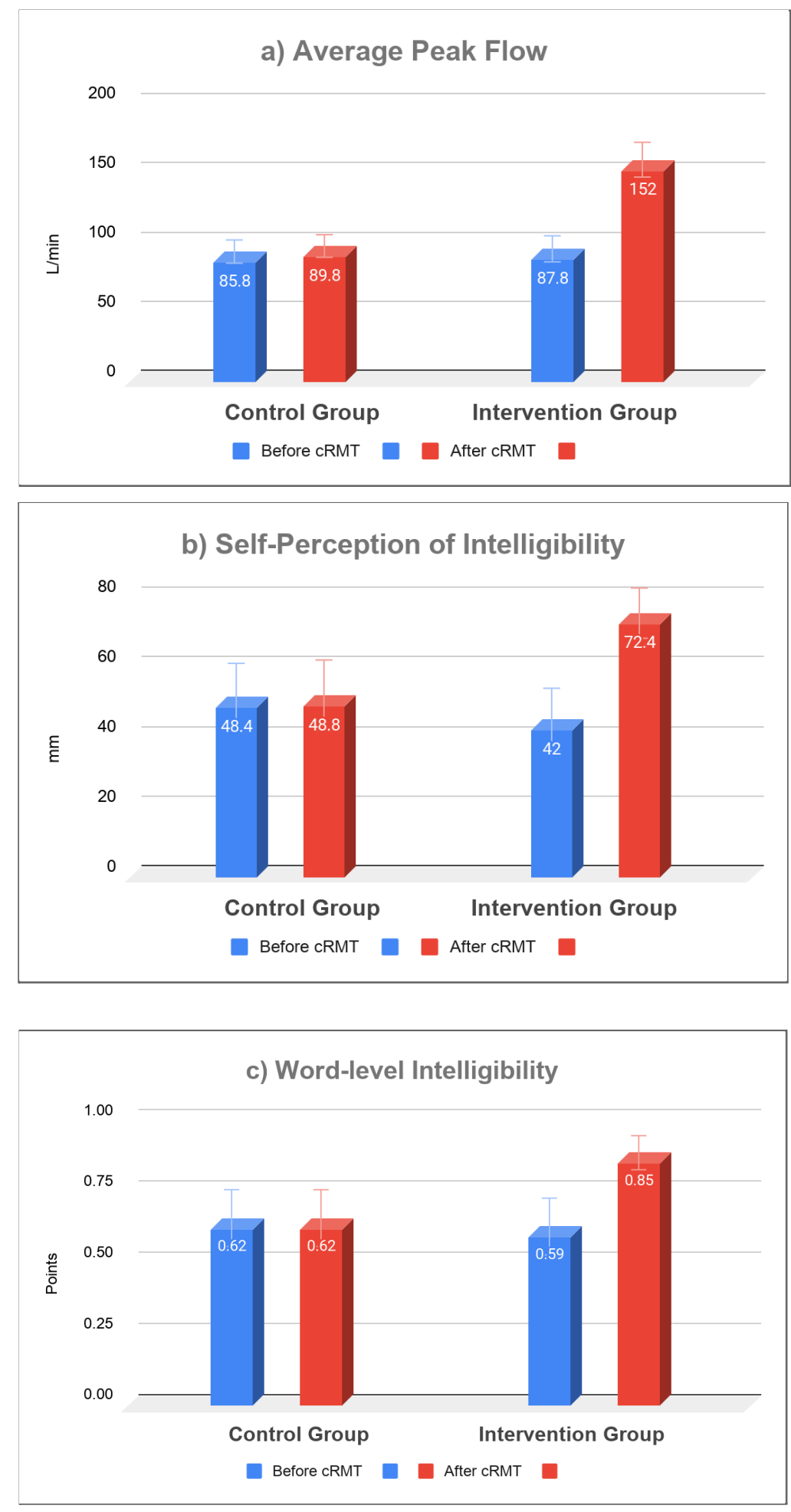

Figure 1: Four weeks of cRMT significantly improve average peak flow (a), self-perception of intelligibility (b) and world-level intelligibility (c) in the intervention group, but not in the control group. Error bars indicate standard error. 
medRxiv preprint doi: https://doi.org/10.1101/2021.05.01.21256463; this version posted May 4, 2021. The copyright holder for this preprint

\section{Discussion}

This retrospective pilot study sought to determine the effectiveness of 4 weeks of 3 intensive brief daily sessions of cRMT on the speech intelligibility of stroke survivors with dysarthria. Compared to the control group whose data remained static, all of the participants in the experimental group showed positive gains after 4 weeks of cRMT in peak expiratory flow rate, self-perceived speech intelligibility, and speech intelligibility judged at the word level. This study is unique in its attempt to determine the potential effects of cRMT on speech intelligibility. A recent study found some improvements in selected respiratory dynamics as well as measures of voice perturbation in stroke patients using both inspiratory and expiratory RMT, but no reports of speech intelligibility improvement were included [47]. The improvements in respiratory peak flow and intelligibility measures in this study suggest that cRMT can have a significant impact on patients with stroke-induced dysarthria.

The direct effect of cRMT on peak flow on the participants in the intervention group was not unexpected given the nature and intensity of the training and existing data from other studies $[36,37,51]$. It is likely that the experimental group participants experienced an increase in both inspiratory strength (resulting in higher initial lung volumes for the task), and forced expiratory strength (allowing for higher expiratory flow volume for the task). Both or either of the two effects could potentially explain the average $73 \%$ increase in peak flow for the experimental group. It is also possible that the changes were simply due to a practice effect after spending 4 weeks using the device; participants may have simply improved at the peak flow task. However, the accompanying improvements in both intelligibility measures suggest that the improvements in peak flow may indeed have been an experimental effect.

Both the experimental participants' self-perceived intelligibility and their average word-level intelligibility as perceived by two blinded judges increased significantly after the 4-week cRMT training regimen. However, there was a larger $(72 \%)$ increase in the perception of their own intelligibility than in their word-level intelligibility increase (44\%) as perceived by the judges. This is likely due to the marked difference between intelligibility judged at the word 
medRxiv preprint doi: https://doi.org/10.1101/2021.05.01.21256463; this version posted May 4, 2021. The copyright holder for this preprint

level and at the sentence or conversational level. At the word level, no contextual cues are available to aid a listener in comprehension. It is assumed that the participants in the intervention group had an increase in word-level intelligibility because they were speaking with a higher initial lung volume after practicing taking more forceful inhalations. It is difficult to predict from these data what their sentence or conversation-level intelligibility would have been; it may have increased similarly due to speaking with higher lung volumes and the addition of linguistic context, but those gains may have been limited due to decreasing lung volumes across longer utterances. It is significant from a psychosocial standpoint that the experimental participants reported a $72 \%$ percent increase in the perception of their own intelligibility; if they felt that others understood them with less difficulty, this points to the validity of using cRMT for improving the functional intelligibility of dysarthric speech.

It is possible as well that the gains in both measures of intelligibility occurred due to an increase in the participants' baseline subglottal pressure, and therefore vocal intensity, for speech. It is clear from the LSVT literature $[39,52,53]$ that solely targeting loudness in treatment of hypokinetic dysarthria can have significant positive impact on not just the loudness of speech, but its rate and articulatory precision as well. While no speech tasks were directly targeted in this study, the carry-over effect from cRMT training to improved respiratory function and greater loudness during speech may be responsible for the positive gains seen in this study.

Despite the small sample size and retrospective nature of this study, the magnitude of the observed gains in peak flow and intelligibility measures are rather striking. The fact that the intelligibility measures improved to such a degree in the experimental group suggests that cRMT could be a viable treatment option for making functional gains in communication for patients with dysarthria. The cRMT device used in this study is a relatively accessible and inexpensive option for treating dysarthria since the task has a relatively low cognitive load. It is important to note that the nature of the training protocol used here, involving a high effort task employed within a high-intensity treatment regimen over a short period of time, adheres 
medRxiv preprint doi: https://doi.org/10.1101/2021.05.01.21256463; this version posted May 4, 2021. The copyright holder for this preprint

to muscle training principles of intensity, specificity and increasing load over time [32]. This fact could explain the magnitude of the gains seen here.

\section{Limitations:}

There are several possible limitations to this study that warrant caution in interpreting the results. The relatively small sample size and retrospective nature of the study are first on this list. The fact that the two groups were similar in their makeup of specific dysarthria types was beneficial for group comparisons; however, the fact that both experimental and control groups had a heterogeneous mix of dysarthria types makes it difficult to generalize the results of the study to specific populations of patients with dysarthria. Furthermore, the nature of this retrospective study is the reason for the lack of a sham-controlled group which would have empowered the study to discern any skewing of data towards a positive outcome and thereby minimize risk of bias. While the gains in word-level intelligibility were significant for the intervention group, it should be noted even though this task represents a more difficult challenge for the listener since there are no context cues, it should be recognized as the easiest for the participants since they are able to produce a single word with higher initial lung volumes. Another limitation of this study is the lack of randomization due to treatment choice by the patient. The next potential limitation is that no assessment was made of the level of general debility or mobility post-CVA as it is possible that the intervention group had an overall physical advantage compared to the control group and may have more easily benefited from respiratory muscle training. Furthermore, no measures of cognitive-linguistic function were reported for the participants, meaning that the peak flow measurements, which require high effort and an understanding of the task, may not be an accurate reflection of true respiratory effort. Finally, no indirect or direct measurements of either subglottal pressure or vocal intensity were made; these measurements could shed light on the potential mechanism of improved intelligibility seen in the experimental participants. 
medRxiv preprint doi: https://doi.org/10.1101/2021.05.01.21256463; this version posted May 4, 2021. The copyright holder for this preprint

(which was not certified by peer review) is the author/funder, who has granted medRxiv a license to display the preprint in perpetuity.

It is made available under a CC-BY-ND 4.0 International license.

\section{Conclusion}

This retrospective study analyzes the use of combined Respiratory Muscle Training (cRMT) with a hand-held device exercising both the muscles of inhalation and exhalation over a four week period revealing significant improvements in peak expiratory flow and speech intelligibility at the word level in the intervention group, as compared to the no treatment control group. In addition, this study also reveals superior patient perception with the intervention group in the domain of others understanding their speech. The present study therefore suggests the effectiveness and feasibility for the inclusion of cRMT in the treatment of persons who present with dysarthria after CVA. Further study is warranted with a double blinded prospective, randomized sham-controlled study to verify these findings in a larger, more diverse population.

\section{Acknowledgements}

The authors thank Sabine Elizabeth French, Ph.D., John F. Richardson, MS, CCC-SLP, Tom Slominski, MA, CCC-SLP, Sigfredo Aldarondo, M.D., FCCP, Tom Berlin, DHSc, RRT, and Betsy Page, MA, CCC-SLP for help with the statistical analysis, critical reading of the manuscript, and helpful comments.

Disclosures and Contributions

CG declares no conflict of interest. NB serves as independent Chief Scientist for PN Medical. RJA declares no conflict of interest. TM declares no conflict of interest.

\section{References}

1. Kunst AE, Amiri M, Janssen $F$. The decline in stroke mortality: exploration of future trends in 7 Western European countries. Stroke. 2011;42: 2126-2130.

2. Arboix A, Martí-Vilalta JL, García JH. Clinical study of 227 patients with lacunar infarcts. Stroke. 1990;21: 842-847.

3. Lloyd-Jones D, Adams RJ, Brown TM, Carnethon M, Dai S, De Simone G, et al. Executive summary: heart disease and stroke statistics--2010 update: a report from the American Heart Association. Circulation. 2010;121: 948-954. 
medRxiv preprint doi: https://doi.org/10.1101/2021.05.01.21256463; this version posted May 4, 2021. The copyright holder for this preprint (which was not certified by peer review) is the author/funder, who has granted medRxiv a license to display the preprint in perpetuity. It is made available under a CC-BY-ND 4.0 International license .

4. Enderby P, Emerson J. Speech and language therapy: does it work? BMJ. 1996;312: $1655-1658$.

5. Lawrence ES, Coshall C, Dundas R, Stewart J, Rudd AG, Howard R, et al. Estimates of the prevalence of acute stroke impairments and disability in a multiethnic population. Stroke. 2001;32: 1279-1284.

6. Miller N, Bloch S. A survey of speech--language therapy provision for people with post-stroke dysarthria in the UK. Int J Lang Commun Disord. 2017;52: 800-815.

7. Brady MC, Clark AM, Dickson S, Paton G, Barbour RS. The impact of stroke-related dysarthria on social participation and implications for rehabilitation. Disabil Rehabil. 2011;33: 178-186.

8. Dickson S, Barbour RS, Brady M, Clark AM, Paton G. Patients' experiences of disruptions associated with post-stroke dysarthria. Int J Lang Commun Disord. 2008;43: 135-153.

9. Wilson RD. Mortality and cost of pneumonia after stroke for different risk groups. J Stroke Cerebrovasc Dis. 2012;21: 61-67.

10. Bowen A, Hesketh A, Patchick E, Young A. ... and service users' perceptions of early, well-resourced communication therapy following a stroke: a randomised controlled trial (the ACT NoW Study). Health Technol. 2012. Available: https://europepmc.org/books/nbk97269

11. Park EJ, Kim JH, Choi YH, Son JE, Lee SA, Yoo SD. Association between phonation and the vowel quadrilateral in patients with stroke: A retrospective observational study. Medicine . 2020;99: e22236.

12. Martino R, Foley N, Bhogal S, Diamant N, Speechley M, Teasell R. Dysphagia after stroke: incidence, diagnosis, and pulmonary complications. Stroke. 2005;36: 2756-2763.

13. Martino R, Pron G, Diamant N. Screening for oropharyngeal dysphagia in stroke: insufficient evidence for guidelines. Dysphagia. 2000;15: 19-30.

14. Darley FL, Aronson AE, Brown JR. Clusters of Deviant Speech Dimensions in the Dysarthrias. Journal of Speech and Hearing Research. 1969. pp. 462-496. doi:10.1044/jshr.1203.462

15. Darley FL, Aronson AE, Brown JR. Differential Diagnostic Patterns of Dysarthria. Journal of Speech and Hearing Research. 1969. pp. 246-269. doi:10.1044/jshr.1202.246

16. Darley FL, Aronson AE, Brown JR. Motor speech disorders. WB Saunders Company; 1975.

17. Johns DF. Clinical Management of Neurogenic Communicative. Prentice Hall; 1985.

18. DWORKIN, P J. Motor Speech Disorders. A Treatment Guide. 1991; 85-132.

19. Weismer G. Motor Speech Disorders: Essays for Ray Kent. Plural Publishing; 2006.

20. Duffy JR. Motor Speech Disorders: Substrates, Differential Diagnosis, and Management. Elsevier Mosby; 2005.

21. Robin DA, Yorkston KM, Beukelman DR. Disorders of motor speech: Assessment, treatment, and clinical characterization. Paul H Brookes Publishing Company; 1996.

22. Till JA, Yorkston KM, Beukelman DR. Motor Speech Disorders: Advances in Assessment and Treatment. P.H. Brooks Publishing Company; 1994.

23. Yorkston KM, Beukelman DR. Assessment of Intelligibility of Dysarthric Speech. C.C. Publications; 1981.

24. Robin DA, Luschei ES. Patent. 5,119,831.

25. Arnold RJ. Patent. 6,050,961.

26. Robbins JA et al. Patent. 6,702,765.

27. Arnold RJ, Mann GD. An Introdution to the Oromotor Dynanometer. Annual Meeting of the American Speech-Language-Hearing Association; 2004.

28. Hardy JC. Intraoral breath pressure in cerebral palsy. J Speech Hear Disord. 1961;26: 309-319.

29. Hardy JC. Suggestions for Physiological Research in Dysarthria. Cortex. 1967;3: 128-156.

30. Hardy JC. Respiratory physiology: implications of current research. ASHA. 1968;10: 204-206.

31. Nicholson P, Covelli JL. Better Breathing - a self teaching manual, 4th edition. PAL-Medical, Inc; 1989.

32. McConnell A. Respiratory Muscle Training E-Book: Theory and Practice. Elsevier Health Sciences; 2013.

33. Chaitow L, Bradley D, Gilbert C. Recognizing and Treating Breathing Disorders E-Book. Elsevier Health Sciences; 2014.

34. Sapienza CM, Troche MS. Respiratory Muscle Strength Training: Theory and Practice. Plural Publishing; 2011.

35. Sapienza C, Hoffman B. Respiratory Muscle Strength Training. Plural Publishing; 2020.

36. Arnold RJ, Bausek N. Effect of respiratory muscle training on dysphagia in stroke patients-A retrospective pilot study. Laryngoscope Investigative Otolaryngology. 2020;n/a. doi:10.1002/lio2.483

37. Arnold RJ, Gaskill CS, Bausek N. Effect of Complete Respiratory Muscle Training (cRMT) on 
medRxiv preprint doi: https://doi.org/10.1101/2021.05.01.21256463; this version posted May 4, 2021. The copyright holder for this preprint (which was not certified by peer review) is the author/funder, who has granted medRxiv a license to display the preprint in perpetuity. It is made available under a CC-BY-ND 4.0 International license.

Dysphonia following Single CVA: A retrospective pilot study. medRxiv. 2020. Available: https://www.medrxiv.org/content/10.1101/2020.12.20.20248589v1.abstract

38. Sapienza C, Hoffman B. Voice Disorders, Fourth Edition. Plural Publishing; 2020.

39. Ramig L, Halpern A, Spielman J, Fox C, Freeman K. Speech treatment in Parkinson's disease: Randomized controlled trial (RCT). Mov Disord. 2018;33: 1777-1791.

40. Mahler LA, Ramig LO. Intensive treatment of dysarthria secondary to stroke. Clin Linguist Phon. 2012;26: 681-694.

41. Jones HN, Donovan NJ, Sapienza C, Shrivastav R, Rosenbek JC. Expiratory Muscle Strength Training in the Treatment of Mixed Dysarthria in a Patient with Lance-Adams Syndrome. J Med Speech Lang Pathol. 2006;14: 207-217.

42. Beukelman DR, Fager S, Ball L, Dietz A. AAC for adults with acquired neurological conditions: a review. Augment Altern Commun. 2007;23: 230-242.

43. Yamagishi J, Veaux C, King S, Renals S. Speech synthesis technologies for individuals with vocal disabilities: Voice banking and reconstruction. Acoust Sci Technol. 2012;33: 1-5.

44. VocaliD - Your voice Al company, bringing things that talk to life. [cited 27 Feb 2021]. Available: https://vocalid.ai/

45. Mills T, Bunnell HT, Patel R. Towards personalized speech synthesis for augmentative and alternative communication. Augment Altern Commun. 2014;30: 226-236.

46. Pollock RD, Rafferty GF, Moxham J, Kalra L. Respiratory muscle strength and training in stroke and neurology: a systematic review. Int J Stroke. 2013;8: 124-130.

47. Liaw M-Y, Hsu C-H, Leong C-P, Liao C-Y, Wang L-Y, Lu C-H, et al. Respiratory muscle training in stroke patients with respiratory muscle weakness, dysphagia, and dysarthria - a prospective randomized trial. Medicine . 2020;99: e19337.

48. Nicholson MK. Respiratory Exerciser. Patent. 4,739,987 , 1988.

49. Shaikh S, Vishnu Vardhan GD, Gunjal S, Mahajan A, Lamuvel M. Effect of Inspiratory Muscle Training by Using Breather Device in Participants with Chronic Obstructive Pulmonary Disease (COPD). Available: http://www.ijhsr.org/IJHSR_Vol.9_Issue.4_April2019/12.pdf

50. Shaikh S, Gunjal S. EFFECTIVENESS OF BREATHER DEVICE IN CERVICAL SPINAL CORD INJURY- A CASE REPORT. EPRA International Journal of Multidisciplinary Research. 2019;5: 191-193.

51. Bausek N, Havenga L, Aldarondo S. Respiratory Muscle Training Improves Speech and Pulmonary Function in COPD Patients in a Home Health Setting - a Pilot Study. bioRxiv. 2019. p. 523746. doi: $10.1101 / 523746$

52. Ramig LO, Dromey C. Aerodynamic mechanisms underlying treatment-related changes in vocal intensity in patients with Parkinson disease. J Speech Hear Res. 1996;39: 798-807.

53. Dromey C, Ramig LO, Johnson AB. Phonatory and articulatory changes associated with increased vocal intensity in Parkinson disease: a case study. J Speech Hear Res. 1995;38: 751-764. 